\title{
Synthesis of Nakiterpiosin
}
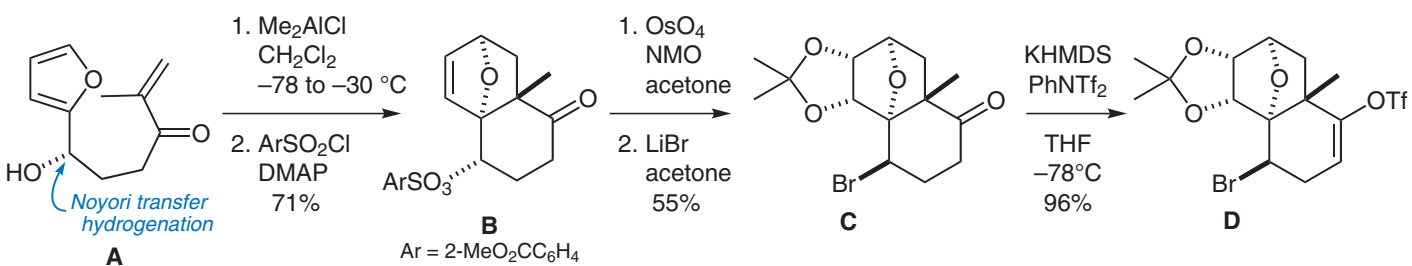

A

\section{Key words}

nakiterpiosin

photo-Nazarov

cyclization

carbonylative cross coupling

Diels-Alder reaction

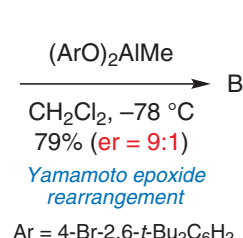<smiles>Cc1c(Br)cccc1[C@H](C=O)C[18OH]</smiles>
$\mathrm{Ar}=4-\mathrm{Br}-2,6-t-\mathrm{Bu}_{2} \mathrm{C}_{6} \mathrm{H}_{2}$ asymmetric epoxidation

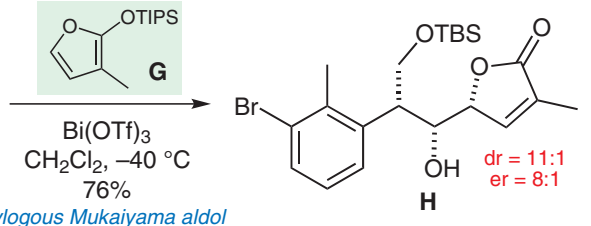
$\mathrm{H}_{2},\left[(\mathrm{cod}) \operatorname{Ir}\left(\mathrm{PCy}_{3}\right)(\mathrm{Py})\right] \mathrm{PF}_{6} \quad$ directed $97 \%(d r=6: 1) \downarrow$ hydrogenation

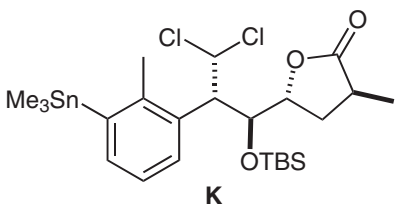<smiles></smiles><smiles>Cc1c(Br)cccc1[C@H](CO[SbH3])[C@H](O)[C@H]1CC(C)C(=O)O1</smiles>
$41 \%$ \begin{tabular}{l|l}
$\begin{array}{l}\text { carbonylative } \\
\text { cross-coupling } 62 \%\end{array}$ & $\begin{array}{l}\text { D, } \mathrm{CO}, \mathrm{Pd}\left(\mathrm{PPh}_{3}\right)_{4} \\
\mathrm{CuCl}, \mathrm{DMSO}, 55{ }^{\circ} \mathrm{C}\end{array}$
\end{tabular}

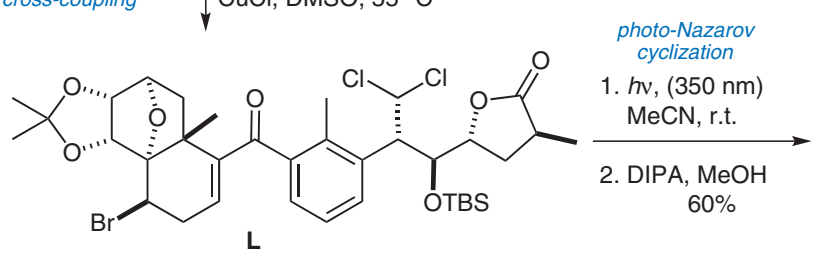
L

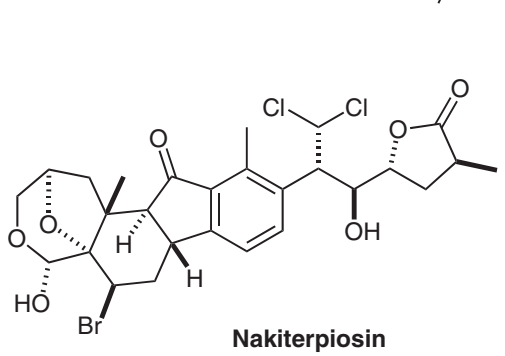

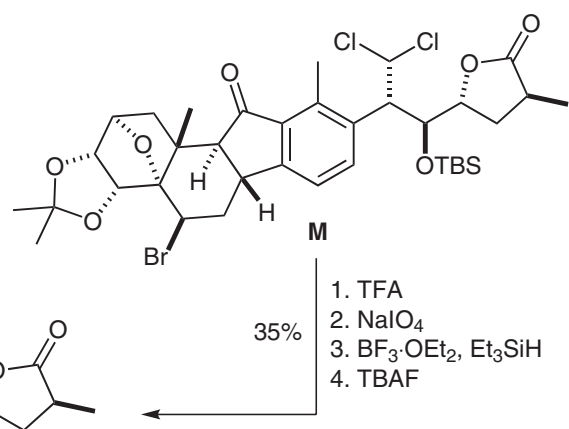

Significance: The synthesis of nakiterpiosin, a cytotoxic sponge metabolite, features a Pdcatalyzed carbonylative cross-coupling $(\mathbf{K} \rightarrow \mathbf{L})$ followed by a photo-Nazarov cyclization $(\mathbf{L} \rightarrow \mathbf{M})$ to create the indanone moiety.
Comment: The photo-Nazarov cyclization entails a thermal electrocyclization induced by photoisomerization of the enone $\mathbf{L}$. Lewis acid catalyzed variants were too harsh. $\mathrm{CuCl}$ and DMSO dramatically enhanced the rate of the crosscoupling $\mathbf{K} \rightarrow \mathbf{L}$.

SYNFACTS Contributors: Philip Kocienski

Synfacts 2009, 7, 0703-0703 Published online: 22.06.2009

DoI: 10.1055/s-0029-1217242; Reg-No.: K06509SF 